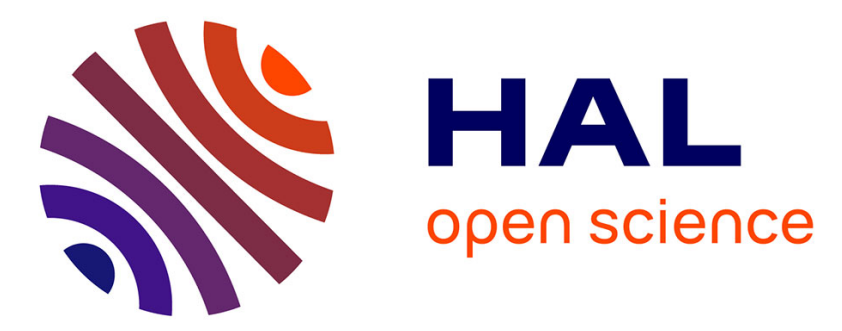

\title{
Ectopic expression of dehydration responsive element binding proteins (StDREB2) confers higher tolerance to salt stress in potato
}

Donia Bouaziz, Julien Pirrello, Hela Ben Amor, Asma Hammami, Mariam

Charfeddine, Amina Dhieb, Mondher Bouzayen, Radhia Gargouri-Bouzid

\section{To cite this version:}

Donia Bouaziz, Julien Pirrello, Hela Ben Amor, Asma Hammami, Mariam Charfeddine, et al.. Ectopic expression of dehydration responsive element binding proteins (StDREB2) confers higher tolerance to salt stress in potato. Plant Physiology and Biochemistry, 2012, vol. 60, pp. 98-108. 10.1016/j.plaphy.2012.07.029 . hal-00994149

\section{HAL Id: hal-00994149 \\ https://hal.science/hal-00994149}

Submitted on 21 May 2014

HAL is a multi-disciplinary open access archive for the deposit and dissemination of scientific research documents, whether they are published or not. The documents may come from teaching and research institutions in France or abroad, or from public or private research centers.
L'archive ouverte pluridisciplinaire HAL, est destinée au dépôt et à la diffusion de documents scientifiques de niveau recherche, publiés ou non, émanant des établissements d'enseignement et de recherche français ou étrangers, des laboratoires publics ou privés. 


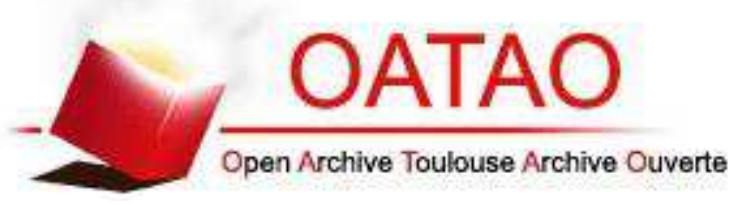

Open Archive Toulouse Archive Ouverte (OATAO)

OATAO is an open access repository that collects the work of Toulouse researchers and makes it freely available over the web where possible.

This is an author-deposited version published in: http://oatao.univ-toulouse.fr/ Eprints ID: 11377

DOI:10.1016/j.plaphy.2012.07.029

Official URL: http://dx.doi.org/10.1016/j.plaphy.2012.07.029

\section{To cite this version:}

Bouaziz, Donia and Pirrello, Julien and Ben Amor, Hela and Hammami, Asma and Charfeddine, Mariam and Dhieb, Amina and Bouzayen, Mondher and Gargouri-Bouzid, Radhia Ectopic expression of dehydration responsive element binding proteins (StDREB2) confers higher tolerance to salt stress in potato. Plant Physiology and Biochemistry . ISSN 0981-9428

Any correspondence concerning this service should be sent to the repository administrator: staff-oatao@inp-toulouse.fr 


\title{
Ectopic expression of dehydration responsive element binding proteins (StDREB2) confers higher tolerance to salt stress in potato
}

\author{
Donia Bouaziz ${ }^{\mathrm{a}, *}$, Julien Pirrello ${ }^{\mathrm{b}, \mathrm{c}}$, Hela Ben Amor ${ }^{\mathrm{a}}$, Asma Hammami ${ }^{\mathrm{a}}$, Mariam Charfeddine ${ }^{\mathrm{a}}$, \\ Amina Dhieb ${ }^{a}$, Mondher Bouzayen ${ }^{\mathrm{b}, \mathrm{c}}$, Radhia Gargouri-Bouzid ${ }^{\mathrm{a}}$ \\ a Laboratoire des Biotechnologies Végétales Appliquées à l'Amélioration des Cultures, Ecole Nationale d'Ingénieurs de Sfax, Route Soukra Km 4, BP 1173, 3038 Sfax, Tunisia \\ ${ }^{\mathrm{b}}$ Université de Toulouse, INP-ENSA Toulouse, Génomique et Biotechnologie des Fruits, Avenue de l'Agrobiopole BP 32607, Castanet-Tolosan F-31326, France \\ ' INRA, UMR990 Génomique et Biotechnologie des Fruits, Chemin de Borde Rouge, Castanet-Tolosan F-31326, France
}

Keywords:

Abiotic stresses

DREB

Solanum tuberosum

Transcription factor

Transgenic plants

\begin{abstract}
A B S T R A C T
Dehydration responsive element binding proteins (DREB) are members of a larger family of transcription factors, many of which have been reported to contribute to plant responses to abiotic stresses in several species. While, little is known about their role in potato (Solanum tuberosum). This report describes the cloning and characterization of a DREB transcription factor CDNA, StDREB2, isolated from potato (cv Nicola) plants submitted to salt treatment. Based on a multiple sequence alignment, this protein was classified into the A-5 group of DREB subfamily. Expression studies revealed that StDREB2 was induced in leaves, roots and stems upon various abiotic stresses and in response to exogenous treatment with abscisic acid (ABA). In agreement with this expression pattern, over-expression of StDREB2 in transgenic potato plants resulted in enhanced tolerance to salt stress. These data suggest that the isolated StDREB2 encodes a functional protein involved in plant response to different abiotic stresses.

An electrophoretic mobility shift assay (EMSA) indicated that the StDREB2 protein bound specifically to the DRE core element (ACCGAGA) in vitro. Moreover, Semi quantitative RT-PCR analysis revealed that the transcript level of a putative target gene i.e. $\delta^{1}$-pyrroline-5-carboxylate synthase (P5CS) was upregulated in transgenic plants submitted to salt stress conditions. A concomitant increase in proline accumulation was also observed under these conditions.

Taking together, all these data suggest that StDREB2 takes part in the processes underlying plant responses to abiotic stresses probably via the regulation of $A B A$ hormone signaling and through a mechanism allowing proline synthesis.
\end{abstract}

\section{Introduction}

Environmental stresses, such as drought, high salt and low temperature adversely affect plants growth and their productivity. Response to abiotic stresses is a very complex phenomenon as various stages of plant development can be affected by a particular stress and often several stresses simultaneously affects the plant $[1,2]$. To better understand how plants adapt to various stresses, it is important to explore how different response pathways interact with each other.

Abbreviations: DREB, Dehydration Responsive Element Binding proteins; CBF, C-repeat Binding Factor; ABA, Abscisic Acid; ERF, Ethylene Response Factors; P5CS, $\delta$-pyrroline-5-Carboxylate Synthase.

* Corresponding author. Tel./fax: +216 74665190.

E-mail address: donia.bouaziz@yahoo.fr (D. Bouaziz).
Many transcriptional factors involved in these stress-resistance pathways have been identified, among which the droughtresponsive element binding factors (DREBS) and C-repeat Binding Factors $(C B F)$ that belong to AP2/ERF super family [3]. The DREB/ $C B F s$ transcription factors are involved in plant response to environmental stresses such as cold and drought [3,4]. They are considered as the best studied group of transcriptional factors involved in abiotic stress response. The DREB factors activate the expression of several target genes that are responsible for controlling correlated characters such as osmoprotection and metabolism [2,5]. These proteins can specifically bind to Dehydration-responsive element (DRE)/C-repeat (CRT), and mediate transcription of target genes [3]. The DRE/CRT is one of the major cis-acting elements which function in either ABA-responsive or non-responsive gene expression during abiotic stresses [2,6].

$D R E B / C B F$-like gene was firstly isolated in Arabidopsis [3] and subsequently identified in a wide variety of plants, including wheat 
(Triticum aestivum L.) [7], barley (Hordeum vulgare L.) [8] and rice (Oryza sativa L.) [9]. The CBF/DREB group, previously classified in the A subfamily [10] of the ERF superfamily, was then divided into different groups I, II, III (DREB1) and IV (DREB2), based on the sequence similarities of the AP2/ERF domain and conservation of other specific motifs present in the ERF proteins [11]. DREB factors showed variation in some conserved motifs and in their biological functions in different species. They are also involved in separate signal transduction pathways involved in abiotic stress responses $[2,9]$.

The differential transcript regulation and functional analysis of $D R E B$ genes was reviewed in Agarwal et al. [12].

Expression of DREB1-type genes was specifically induced by low-temperature stress in Arabidopsis and rice [9,10]. In contrast, DREB2-type genes responded to dehydration and high-salt stresses [9]. Recently, a DREB1-type gene from hot pepper (Ca-DREBLP1), was found to be induced by water-deficit and salt stress and to a lesser extent by mechanical wounding whereas it was not induced by cold stress [12,13]. Other DREB1-type genes, such as soybean (GmDREB2) and Caragana korshinskii (CkDREB), were induced by drought, high-salt and low-temperature stresses, as well as by ABA treatment $[14,15]$. Wheat TaDREB1 and WDREB2, maize ZmDREB2A, and pearl millet PgDREB2, DREB2-type genes are responsive to cold stress as well, whereas foxtail millet SiDREB2 was not $[2,9,16-20]$. The maize DREB2-type gene (ZmDREB2A), was shown also to accumulate under heat stress at seedling stage [19].

It was shown that DREB factors activate the stress response through DREs in ABA-independent manner [21]. However, DREB proteins have been also reported to be engaged in an ABA-mediated gene expression pathway [22,23]. Recently, DREB1A/CBF3, DREB2A, and DREB2C proteins have been reported to physically interact with AREB/ABF proteins.

$[2,23,24]$, which supports the view that DREB/CBFs and AREB/ ABFs may interact to control ABA-regulated gene expression. Moreover, in soybean, the expression pattern of the GmDREB2 gene suggests that it acts as an overlap point and might take part in both ABA-dependent and independent pathways, simultaneously $[2,14,21]$. Similarly, the expression of WDREB2 from wheat was shown to be responsive to exogenous ABA treatment [17,21,23], whereas transgenic tobacco plants overexpressing this gene were hypersensitive to exogenous ABA during post germination growth compared with wild-type tobacco [21,25], thereby suggesting that wheat DREB2 might contribute indirectly to the development of abiotic stress tolerance through an increase in ABA sensitivity. In the case of maize (Zea mays), DRE-binding AP2/ERF domain factors, DBF1 and DBF2, are shown to be not only ABA inducible but they also regulate $A B A$ response in vivo [23,26]. All, these observations suggest that DRE/CRT-regulated expression of some genes may be ABA dependent [2]. These studies highlight that there is a crosstalk during stress signaling, mediated by a synergistic effect of ABA and drought/salt stress, for the regulation of stress responsive genes [27].

In addition, DREBs are considered as candidate genes for stress tolerance engineering and also in marker-assisted selection (MAS) to develop stress tolerant crop varieties [2].

Many DREB1-type genes inserted into plants by transformation were capable of improving multiple abiotic stress tolerances in agricultural crops including tobacco [28], wheat [29], rice [9], Chrysanthemum [30], C. korshinskii [15], and potato [31].

Potato (Solanum tuberosum L.) is a major food crop worldwide with premier economic importance. However, due to its sparse and shallow root system, this species is very sensitive to environmental stresses such as high salinity, drought, and severe temperature changes. Consequently, tuber yield can be considerably reduced by such stresses, and efforts to investigate the mechanisms of molecular adaptation to stresses aiming to open new leads toward strengthening stress tolerance are of fundamental importance for potato production. Up to date, no DREBs from S. tuberosum have been characterized. However, increased salt tolerance has been observed in transgenic potato lines harboring Arabidopsis rd29A::DREB1A gene [32,33]. Moreover, the Arabidopsis rd29A::DREB1A seemed also able to improve the response of transgenic potato plants to freezing [34], suggesting that the control of tolerance to abiotic stress in potato, is mediated by DREB factors. Similarly, ectopic AtCBF1 overexpression enhanced freezing tolerance and induced cold acclimationassociated physiological modifications in potato [31].

The present report describes the isolation and functional characterization of a DREB gene (StDREB2) in potato. It is shown that StDREB2 transcript accumulation rapidly increases in response to salt, cold and drought treatment suggesting an active role for this gene in the adaptation mechanisms to abiotic stresses. The data also indicate that StDREB2 expression is dependent on an active abscisic acid (ABA) signaling pathway. In line with the abiotic stress-associated pattern of expression, transgenic potato plants over-expressing the StDREB2 gene, exhibited enhanced tolerance to salt stress.

\section{Results}

\subsection{Isolation and sequence analysis of the StDREB2 full length CDNA}

A full-length cDNA clone corresponding to a potato DREB gene was obtained using the Gateway technology which is a universal cloning method based on the site-specific recombination properties of lambda bacteriophage [35]. To enable recombinational cloning and efficient selection of entry or expression clones, most Gateway ${ }^{\circledR}$ vectors contain two att sites (from lambda bacteriophage) flanking the cloning cassette. After a recombination reaction, this cassette is replaced by the gene of interest to generate the entry clone or the expression clone.

The isolated cDNA, designated StDREB2 (S. tuberosum droughtresponsive element binding factor 2; GenBank ID: JN125858) possesses an open reading frame (ORF) of 438 bp encoding a putative protein of 146 amino acids. A sequence alignment revealed the presence of the conserved AP2/ERF central 58 amino acids located in the $\mathrm{N}$-terminal position and harboring valine residue at position 14 and glutamic acid at position 19 which both characterize DREB members [10] (Fig. 1A). Transcription factors, that share functionally important domains involved in transcriptional activity and protein-protein interactions can be classified in the same subgroup and the presence of common motifs within a subgroup may suggest shared functions [36]. In silico analysis of StDREB2 encoded protein indicated that it shares high similarities with several DREB proteins belonging to class II [11] that correspond to A5 group [10]. Indeed, the sequence comparison of the overall amino acid sequence shows that StDREB2 share 66, 70, 72 and 57\% amino acid similarity with Glycine max L. GmDREB1 and GmDREB2, the Gossypium hirsutum GhDBP1, and Arabidopsis RAP2.1 respectively (Fig. 1A).

Moreover, StDREB2 contains the EAR repressor motif located in the C-terminal domain (ERF-associated amphiphilic repression) defined as CMII-2 [11].

A phylogenetic analysis (Fig. 1B) performed using the MEGA4.0 program allowed classification of StDREB2 into the A-5 subgroup of DREB subfamily [10], besides GhDBP1 (G. hirsutum), RAP2.1 (Arabidopsis), GmDREB1 and GmDREB2 (G. max L).

\subsection{Expression pattern of the StDREB2 gene in plants submitted to salt stress}

To determine the tissue-specific expression pattern of the StDREB2 gene under different stress conditions, we monitored the 
level of its mRNA in different organs by semi-quantitative RT-PCR. Plants cultivated in vitro were submitted to two different concentrations of $\mathrm{NaCl}(100$ and $200 \mathrm{mM}$ ) for $24 \mathrm{~h}$ and semi-quantitative RT-PCR experiments were then performed on RNA extracted from stressed and unstressed control plants. In the absence of salt treatment, StDREB2 transcript accumulation is almost undetectable in all organs tested but it is dramatically increased upon salt treatment at both 100 and $200 \mathrm{mM} \mathrm{NaCl}$ in leaves, stems and roots (Fig. 2). Remarkably, in root tissues, maximum transcript accumulation is already reached with $100 \mathrm{mM} \mathrm{NaCl}$ while in leaves, and to a lesser extent in stems, the expression of StDREB2 continues to increase with the increase in salt concentration ( $200 \mathrm{mM}$ ). This may reflect the fact that roots are in direct contact with salt and/or that root tissues are more sensitive to elevated concentration of $\mathrm{NaCl}$.

\subsection{StDREB2 is highly responsive to abiotic stress and to $A B A$ hormone}

To gain more insight on the stress-induced expression pattern of the StDREB2 gene, plants were submitted during $24 \mathrm{~h}$ to drought and cold abiotic stresses and to ABA hormone. It is commonly admitted that DREB transcription factor are involved in plant responses to abiotic stresses through $\mathrm{ABA}$-independent manner [12]. To better characterize the stress-dependent expression of this gene, the StDREB2 transcript accumulation was investigated in leaves, stems and roots (Fig. 3 ) at different treatment periods (3, 6, 9, and $24 \mathrm{~h}$ ). Semi quantitative RT-PCR analysis showed that the transcription of StDREB2 gene is responsive to drought, and cold stresses but also to ABA treatment in all tested organs with variable expression patterns.

In leaves, the ABA and PEG treatments, resulted in a substantial increase in StDREB2 transcript levels within $3 \mathrm{~h}$, this expression remained high throughout $24 \mathrm{~h}$ of treatments (Fig. 3A). Low temperature treatment also induced an increase in StDREB2 transcript accumulation but after $9 \mathrm{~h}$ of culture at $4{ }^{\circ} \mathrm{C}$. However, this increase was lower than that observed for plants submitted to osmotic stress. These results suggest that StDREB2 seems to be more related to osmotic stress than low temperature.

In stems (Fig. 3B), the ABA treatment, led to the increase in StDREB2 expression transcription and the expression pattern was similar to that observed in leaves. However, PEG and cold treatments induced low increase in StDREB2 transcription. Within $6 \mathrm{~h}$ the StDREB2 mRNA remained lower than that detect in leaves.

In roots (Fig. 3C), the expression pattern of StDREB2, in response to drought treatment, was similar to that found in leaves, while the transcript level of StDREB2 increased by cold and ABA treatments after $6 \mathrm{~h}$ of treatment.

These data clearly show that, the expression of StDREB2 was induced by $A B A$ in all tested organs. These results suggest that unlike DREB1-type and DREB2-type transcription factors, StDREB2 seems to be responsive to ABA phytohormone signal and it's likely to be involved in ABA-dependent signal pathways.

These data are in agreement with those reported previously for other DREB genes from different plant species such as barley HvDRF1 and wheat TaDREB2 and TaAIDFa $[17,37,38]$. Similar results were also reported in soybean GmDREB2, another member of the A-5 group of the DREB subfamily, which was significantly induced by $\mathrm{ABA}, \mathrm{NaCl}$ and drought treatment [14].

Together with other reports, these data suggest that DREB proteins may be involved in a pathway regulated by ABA.

Few reports described the tissue-specific expression of $D R E B$ s. Indeed, expression of AtDREB2A and AhDREB1 was observed in roots, stems and leaves under standard growth conditions. However, under salt stress conditions, AhDREB1 was shown to be highly expressed in roots but less significantly in stems and leaves [39].
The transcription of soybean GmDREBa and GmDREBb was induced by cold, drought and salt in leaves, whereas, the expression of $G m D R E B C$ was not significant in leaves but showed high expression level in roots following drought, salt and ABA treatments [40].

\subsection{StDREB2 is a DRE box-binding protein}

Electrophoretic mobility shift assay (EMSA) is generally used to determine whether a given DNA binding protein can interact with related DNA sequences. This technique was used to investigate whether the isolated StDREB2 protein can bind to a DREbox. To this aims the StDREB2-His tag fusion protein was expressed in Escherichia coli and it was subsequently purified (data not shown).

As shown in Fig. 4, the purified His-StDREB2 protein bound specifically to the DRE motif (ACCGAGA) and produced a retarded band on polyacrylamide gel (Fig. 4, lane 5). However, mutated DRE elements (mDRE) with all base mutations in the DRE core sequence showed no binding with His-StDREB2 fusion protein (Fig. 4, lane 4).

As a negative control, no retardation band was detected when the purified His-tag (expressed and purified from the native pET14b (+) expression vector in E. coli BL21 (DE3) cells) was lowed alone (Fig. 4, lane 3). These results suggest that StDREB2 protein can specifically bind to the wild-type DRE motif (ACCGAGA) in vitro.

\subsection{Generation of transgenic potato lines over-expressing StDREB2}

Potato leaves and internodes from Spunta cultivar were used to regenerate transgenic plants overexpressing StDREB2 cDNA. A stable transformation was obtained using Agrobacterium tumefaciens carrying a sense construct allowing ectopic expression of StDREB2 under the control of CaMV-35S promoter (Fig. 5). Regenerated plantlets that successfully rooted in the presence of $3 \mathrm{mg} \mathrm{l}^{-1}$ hygromycin were multiplied in vitro and screened by PCR for the presence of the transgene.

Since potato is a tetraploid clonal crop multiplied by tuber seeds and because multiplication of plants under green house conditions didn't allow flowering of its tetraploid status, transgenic plants from To generation were used in this study [41].

To this end, a first set of primers corresponding to the internal sequence of the CaMV35S promoter was used in a PCR reaction on genomic DNA extracted from the different plants (Fig. 6). The expected $300 \mathrm{bp}$ fragment was detected in all putative transgenic lines (Fig. 6A). Thereafter, the presence of the StDREB2 transgene in the selected plants was confirmed by a second PCR performed using primers specific for the sequences flanking the transgene (pMDC32 primers; Fig. 5). A 650 bp amplification fragment was observed for all the selected plants validating the presence of the StDREB2 transgene in these transformed lines. The native binary vector was used as positive control and an amplification of $1796 \mathrm{bp}$ corresponding to the region harboring the specific primers of this vector was detected (Fig. 6B).

In order to distinguish between the transcript corresponding to the StDREB2 transgene and the endogenous one, the expression level was assessed by semi-quantitative RT-PCR assays using pMDC32 primers. An analysis was performed on RNA extracts from plants cultivated in the absence or the presence of $200 \mathrm{mM}$ of $\mathrm{NaCl}$. The result revealed high levels of transcript accumulation corresponding to the StDREB2 transgene under stress conditions, while no amplification was obtained in wild-type (SP) plants neither in the absence nor in the presence of stress (Fig. 7). 
A

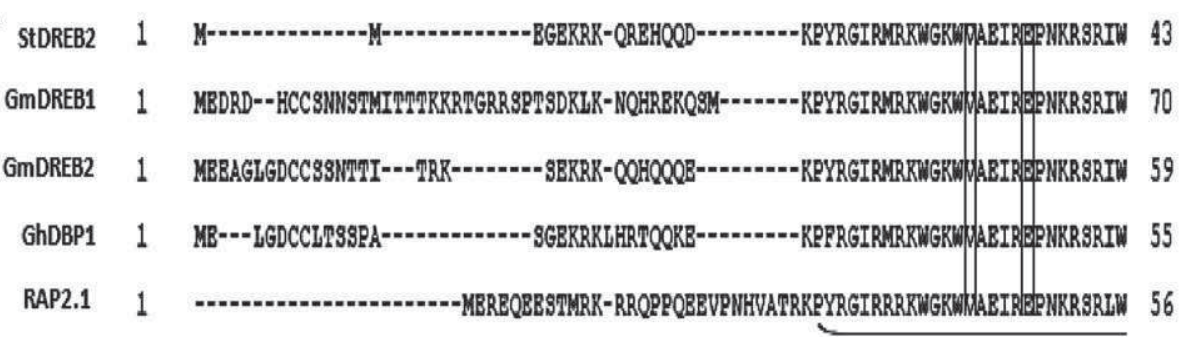

ERF domain

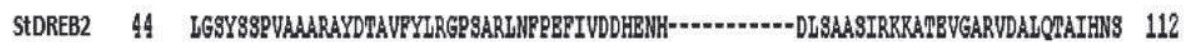

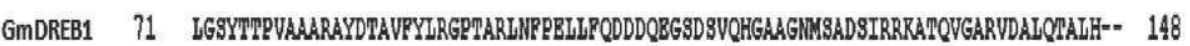

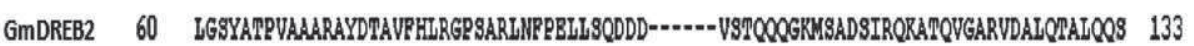

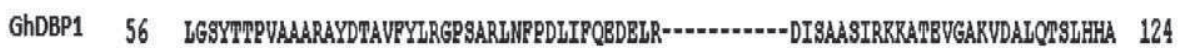

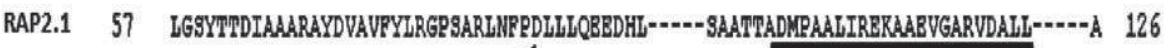

CMII-1

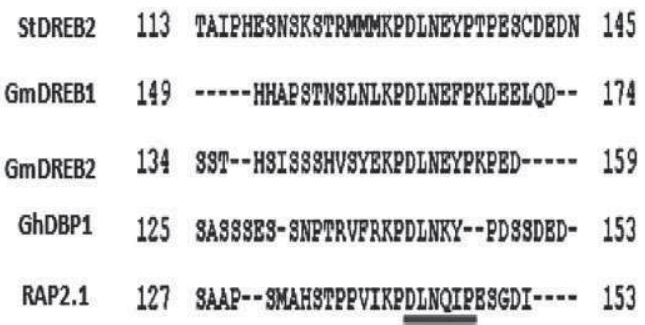

CMII-2(EAR)

B

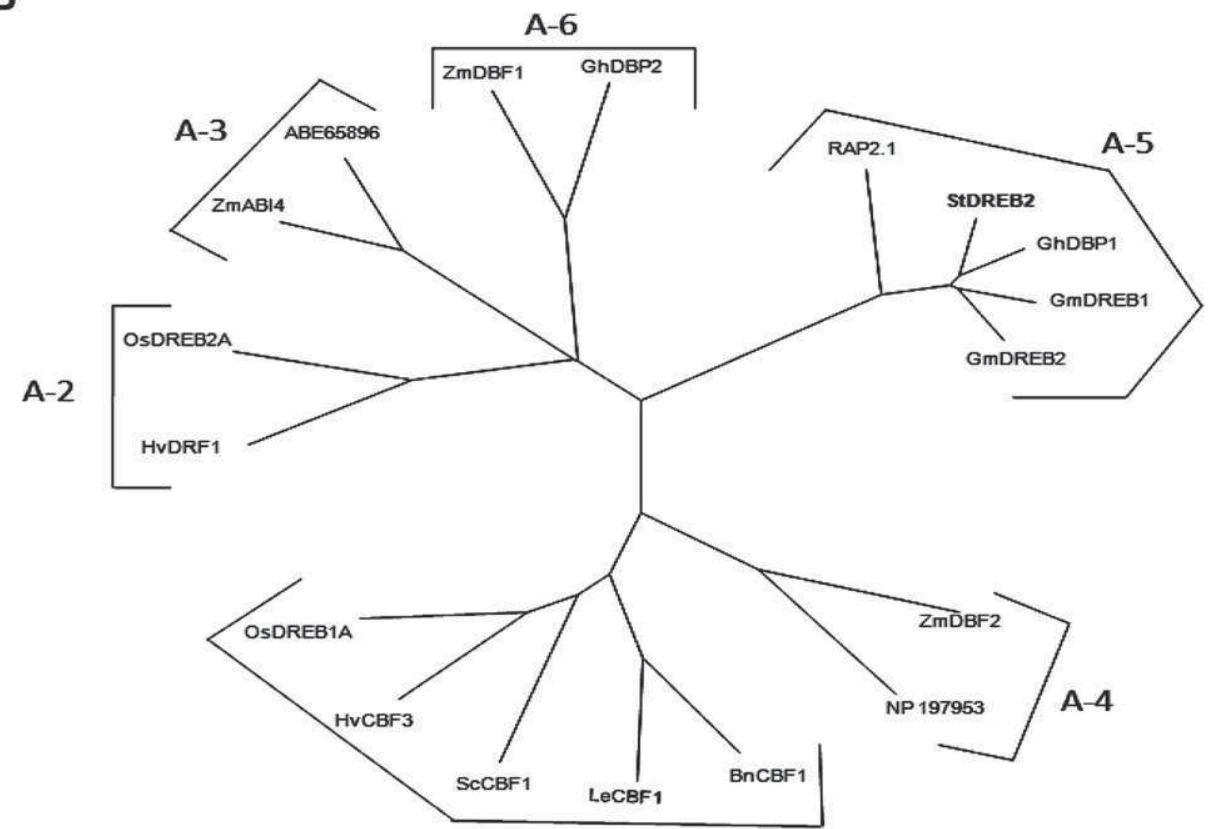

A-1

0.1

Fig. 1. Amino acid sequence comparison and phylogenetic relationship of StDREB2 with other plant DREBs. A. Derived amino acid sequence of the isolated StDREB2 cDNA and comparative analysis with its closest DREB homologous from Glycine max L. GmDREB1 (AF514908), GmDREB2 (ABB36645), Gossypium hirsutum GhDBP1 (AY174160) and Arabidopsis RAP2.1 (AY086838). The AP2/ERF domain is presented in brace, the 14th valine and the 19th glutamic acid inside the AP2/ERF domain are presented in box. The gray bar below the sequences indicates the CMVII-2 (EAR) motif and the black bar below the sequences represents the CMII- 1 motif. B. phylogenetic tree of StDREB2 with DREBs from other plants. The phylogenetic tree was constructed by the MEGA program. The scale indicates branch lengths. A-1-A-6 indicate subgroups proposed by Sakuma et al. [10]. The accession number of each appended protein is: BnCBF1 (AF370733); LeCBF1 (AY034473); ScCBF1 (AF370730); HvCBF3 (AF239616); HvDRF1 (AY223807); OsDREB1A (AF300970); OsDREB2A (AF300971); ZmDBF1 (AF493800); ZmDBF2 (AF493799); ZmABI4 (AY125490); GhDBP1 (AY174160); GhDBP2 (AY619718); GmDREB1 (AF514908); TINY (NP_197953). 


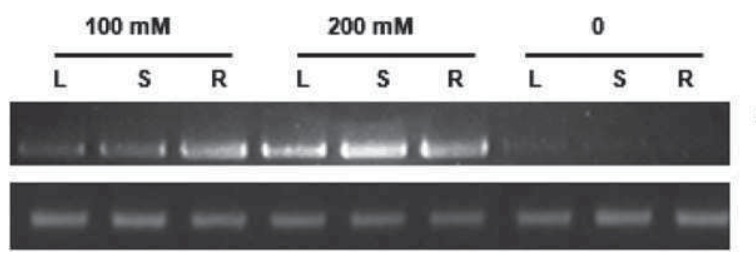

StDREB 2

ef1a

Fig. 2. RT-PCR analysis of StDREB2 gene organ specific expression. The ef $1 \alpha$ was used as control to normalize the amount of templates in PCR. Total RNA was isolated from leaves (L), stems (S), and roots (R) after $24 \mathrm{~h}$ of $\mathrm{NaCl}$ treatment at two concentrations, 100 and $200 \mathrm{mM}$.

\subsection{Overexpression of StDREB2 enhances salt tolerance in transgenic potato plants}

Phenotypic characterization of the selected transgenic potato lines revealed their enhanced vigor compared to wild type plants when cultivated in vitro on MS medium (Fig. 8). To further explore the impact of the ectopic expression of StDREB2, seedlings $(5 \mathrm{~cm}$ height) corresponding to 6 independent transgenic lines and to wild-type potato, were transferred to MS medium containing

A

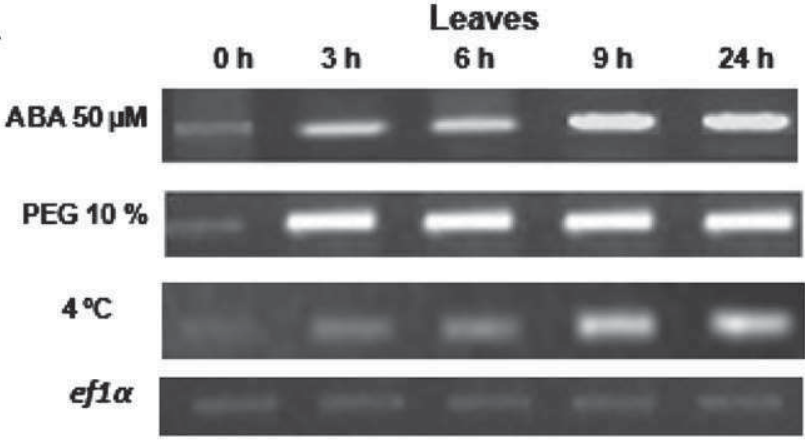

B

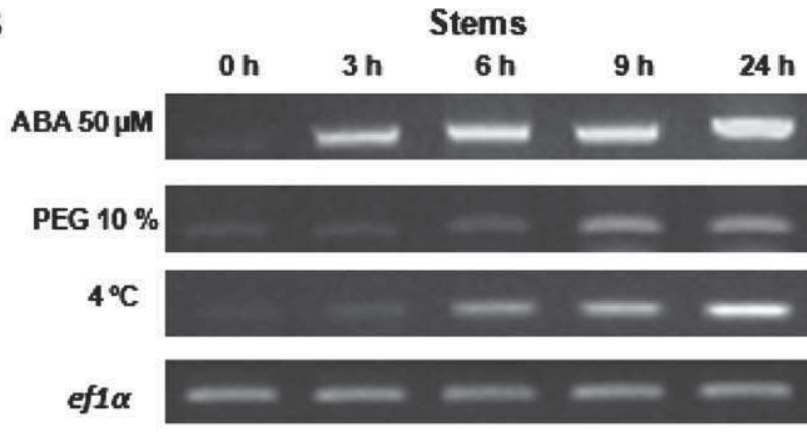

C

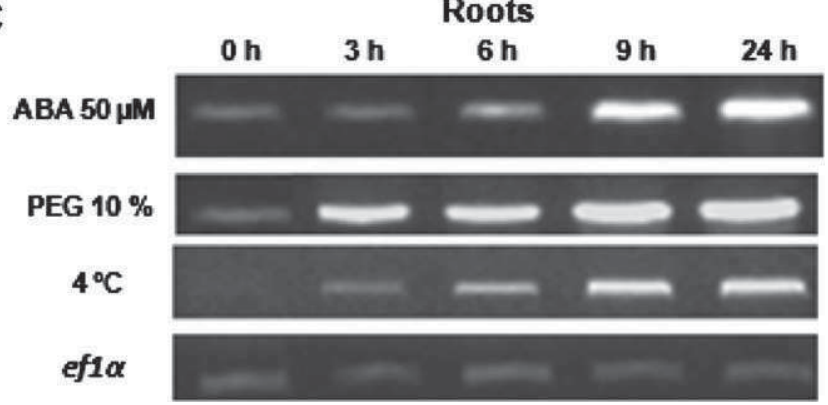

Fig. 3. Transcription pattern of the StDREB2 gene under various stresses at different treatment periods $(0,3,6,9$ and $24 \mathrm{~h})$. A. Expression profiles of StDREB2 RNA in leaves. B. Expression profiles of StDREB2 RNA in stems. C. Expression profiles of StDREB2 RNA in roots.
$200 \mathrm{mM} \mathrm{NaCl}$. After 40 days culture, significant phenotypic differences between wild-type and transgenic lines were observed (Fig. 9). Wild-type SP plants gradually exhibited a substantial loss of leaf greenness and severe inhibition of root formation. By contrast, leaves in transgenic plants remained green, and roots developed normally, with the exception of lines SP 1 and SP B (Fig. 9) which showed a delay in rooting. These data suggest an improved salt tolerance of transgenic potato plants that were able to grow in the presence of $200 \mathrm{mM} \mathrm{NaCl}$. Total chlorophyll content assessed after 40 days culture in the absence of salt treatment was significantly higher in the transgenic lines (Fig. 10). However, a decrease in chlorophyll level was observed in both transgenic and untransformed plants cultivated under salt stress conditions. In control wild type plants, salt stress resulted in a drop of total chlorophyll content from $7.8 \mathrm{mg} \mathrm{g}^{-1} \mathrm{FW}$ to $4.36 \mathrm{mg} \mathrm{g}^{-1}$ FW. Although a decrease in chlorophyll content was also observed in transgenic plants submitted to salt stress, the residual chlorophyll amount remained substantially higher than in control untransformed plants. These data indicate that over-expression of StDREB2 enhanced chlorophyll content in transgenic plants thus suggesting that transcription factor may be involved in the control of chlorophyll biosynthesis or/and degradation as previously reported for other transgenic plants expressing DREB genes $[42,43]$.

\subsection{Determination of relative water content}

Relative water content (RWC) is the appropriate measure of plant water status in terms of the physiological consequence of cellular water deficit. To evaluate physiological changes in transgenic plants after salt stress condition during 20 days, RWC in wild type and different transgenic lines were compared. Under control conditions, the RWC was similar for wild type and the different transgenic plants (Fig. 11), that is, around $0.88-0.92 \mathrm{~g} \mathrm{~g}^{-1}$ FW. However, following stress condition, the RWC in wild-type plants showed a sharp drop and reached only $0.29 \mathrm{~g} \mathrm{~g}^{-1} \mathrm{FW}$, whereas, those in transgenic plants at the same developmental stage decreased much less after 20 days, and reached $0.55-0.91 \mathrm{~g} \mathrm{~g}^{-1} \mathrm{FW}$ respectively for SP G and SP B (Fig. 11).

\subsection{Overexpressing StDREB2 in potato increases proline and activates P5CS gene under salt stress}

It has been reported that proline is involved in osmotic adjustment in plants as one of the crucial factors playing adaptative roles in enhancing plant tolerance to a wide range of environmental stresses [44].

Our data reveal that transgenic potato, carrying StDREB2, exhibited an enhanced tolerance to salt stress, suggesting that osmolyte accumulation may participate in enhancing the stress tolerance of the transgenic plants. To address this possibility, the proline contents in the wild-type and 35S::StDREB2 transgenic potato was measured following salt stress. No significant difference between WT (SP) and StDREB2 transgenic lines was noticed under standard conditions. While, the proline levels in the transgenic lines increased, after 10 days of salt treatment. They remained unchanged in the WT control (Fig. 12A).

The expression of StP5CS gene, which encodes a key enzyme involved in proline synthesis was analyzed by semi quantitative RTPCR performed on RNA from transgenic and non-transgenic potato plants. In silico analysis of potato P5CS putative gene (PGSC0003DMG402026767) revealed that its promoter sequence harbors the DRE (ACCGAGA) target sequence suggesting that it can be a target gene of StDREB2. 


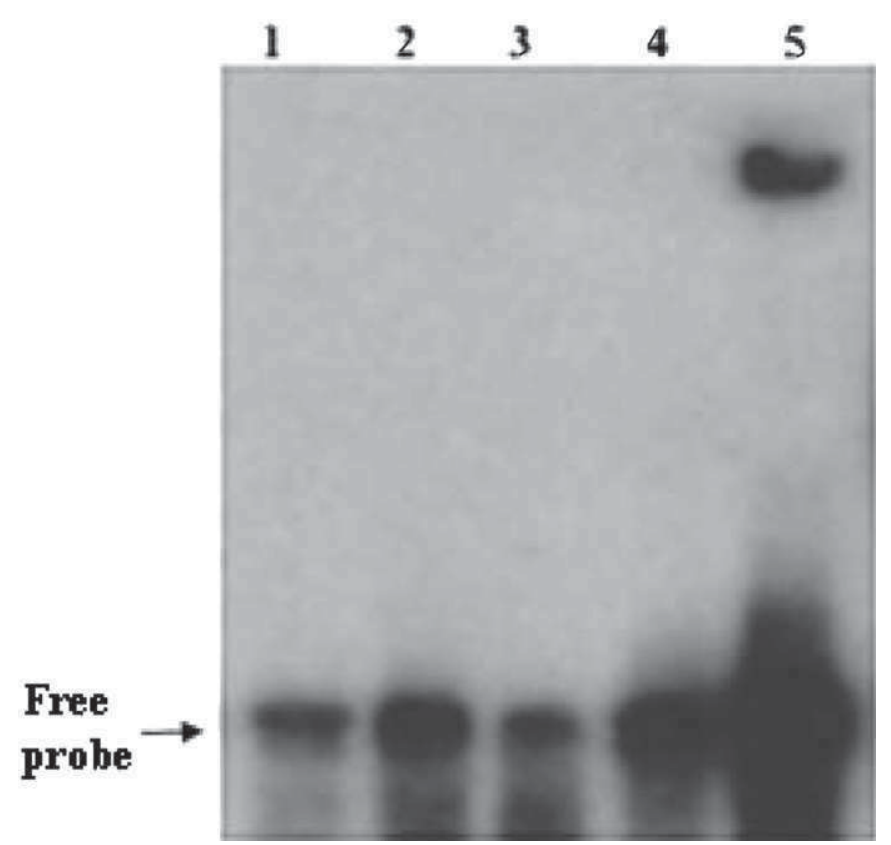

Fig. 4. Characterization of the DNA-binding affinity of the purified His-StDREB2 fusion protein. Lanes 1, 2: the wild type and mutated DRE probes respectively used alone as a negative control; lane 3: His tag incubated with labeled wild-type DRE; lane 4: His-StDREB2 fusion protein incubated with labeled mDRE; lane 5: His-StDREB2 fusion proteins bound to the wild-type DRE.

As shown in (Fig. 12B), a similar expression level of StP5CS gene was noticed in transgenic and non transgenic seedlings cultivated under standard growth conditions. However, when these seedlings were subjected to a salt treatment for 10 day, StDREB2 transgenic lines showed a significant activation of P5CS gene in comparison to WT ones. These results suggest that StDREB2 may activate proline synthesis that contribute to enhance tolerance to salt stress in potato plants.

\section{Discussion}

It was postulated that since the activation of plant defenses and stress responses is metabolically expensive, plants have evolved to keep such responses under tight control during normal growth and development by means of transcription repressors that control stress-related gene expression [45]. For this reason, several studies have focused on the roles of transcription activators in modulating plant defense and stress responses [46]. The present study describes the identification and characterization of StDREB2, a new member of the DREB family of transcription factors in potato, and reveals its involvement in abiotic stress responses. StDREB2 belongs to group II [11] that correspond to A-5 group of DREB family [10].

The alignment of StDREB2 amino acid sequence against DREB proteins revealed that this transcription factor also contains a conserved DLNxxP domain (Fig. 2), which is very similar to the EAR motif (L/F DLN L/F[x]P) identified in several ERF transcriptional repressors of various species [47] suggesting that the StDREB2 might function as a DRE binding transcriptional repressor in potato.

In the same context, it was reported that cotton dehydrationresponsive element (DRE) binding protein 1 (GhDBP1) could function as an active transcriptional repressor for DRE-mediated gene expression and it was demonstrated that GhDBP1's transcriptional repression domain is located in the C-terminus. It is also known as an ERF-associated amphiphilic repression (EAR)-motif. Furthermore, the aspartic acid (D), leucine (L), asparagine (N) and proline $(\mathrm{P})$ amino acid residues are conserved in the EAR-motif, and are found to be necessary for repression through mutational analysis. In addition, transgenic Arabidopsis plants overexpressing GhDBP1 were more sensitive to high salinity stress and appeared to downregulate the expression levels of the stress-induced effector genes [43].

Similarly to GmDREB2 encoding the EAR motif-containing transcription factor from soybean, StDREB2 was rapidly induced by ABA and the accumulation of StDREB2 transcripts in potato was also found to be induced by abiotic stresses (cold, drought and salt) in different plant organs (stem, leaves and roots). ABA is the major plant hormone associated with water stress signaling and it was shown to be essential in regulating plant water balance and osmotic stress tolerance [48]. In line with previous reports on DREB genes [14,43], the data presented here suggest a role for StDREB2 in signaling processes associated with plant responses to various stress conditions.

Since DREs have been reported to be involved in various abiotic stress responses through both ABA-dependent and ABA independent pathways $[9,26]$, an EMSA experiment was performed to confirm that StDREB2 bound specifically to the DRE (ACCGAGA) motif (Fig. 4).

Transgenic potato lines expressing the DREB1A gene derived from Arabidopsis thaliana showed a significant tolerance to salinity $[32,33]$ and enhanced freezing tolerance [34]. In the same context, stress-inducible expression of GmDREB1 conferred salt tolerance in transgenic alfalfa. Similarly, over-expression of GmDREB2 and GmDREB3 can enhance the tolerance of transgenic plants to drought, cold and salt stresses. Since all these GmDREB proteins are classified into A-5 subgroup of DREB family, one can suggest that members of A-5 subgroup are important genetic resources for improving stress tolerance in crop plants [14]. Moreover, overexpression of GhDREB, another member of the A5 group in transgenic wheat improved drought, salt and freezing tolerances [43]. Accordingly, the present study shows that transgenic potato plants over-expressing StDREB2 exhibited increased tolerance to high salinity. Since EAR motif-containing proteins function as transcriptional repressors $[45,47]$, it can be postulated that the enhanced tolerance of transgenic potato plants expressing StDREB2 is conferred through suppressing a negative regulator of the stress tolerance mechanism.

The data presented in this study show that at high salt concentrations, the level of StDREB2 expression increased significantly and a positive correlation between StDREB2 expression and chlorophyll content was observed. Similar results were shown in GhDREB transgenic plants that maintained higher chlorophyll levels

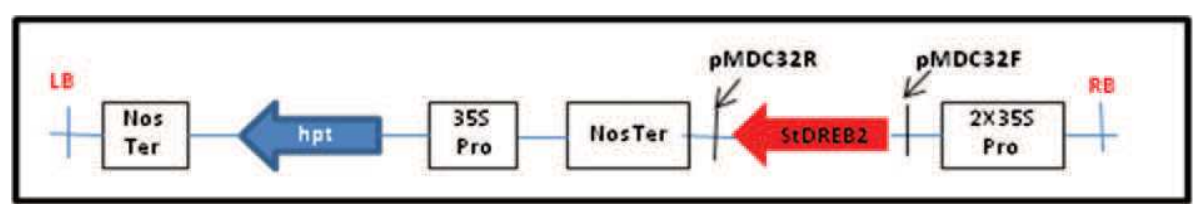

Fig. 5. Construct used to transform potato plants. 2X35S Pro: cauliflower mosaic virus (CaMV) 35S RNA doubled promoter, Nos-Ter: terminator from the nopaline synthase gene, and Agrobacterium T-DNA borders (LB left border and RB right border), pMDC32F and pMDC32R: specifics primers of the binary vector, hpt: hygromycin phosphotransferase gene. 


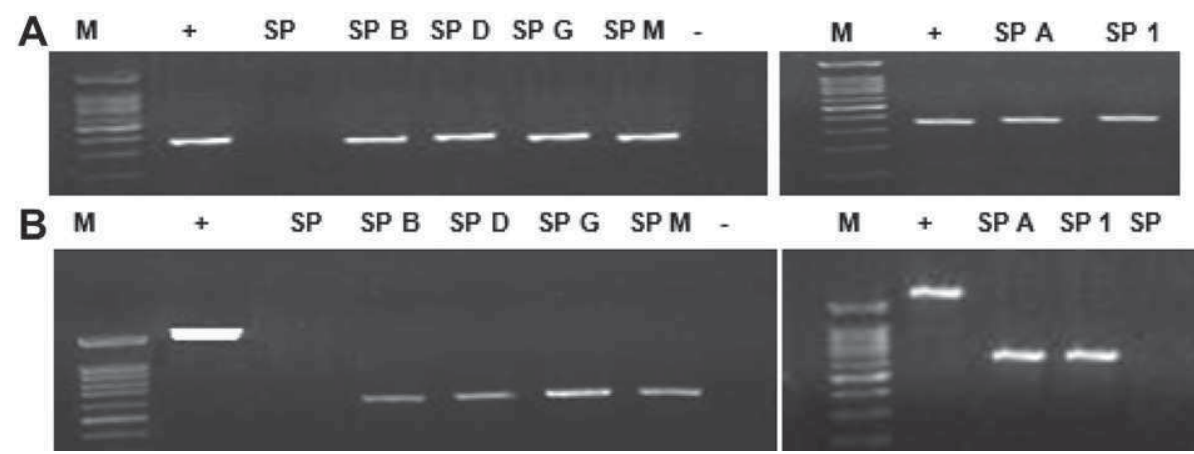

Fig. 6. Identification of StDREB2 transgenic potato plants. A. PCR amplification profile of the CaMV35S sequence from genomic DNA of the different hygromycin resistant plants (SP 1, SP A, SP B, SP D, SP G and SP M). B. PCR amplification of the StDREB2 gene using the pMDC32 specific primers. M: 100 bp DNA Ladder (-): negative control without DNA. (+): positive control PCR from pMDC32 plasmid. SP: Spunta untransformed plant.

than control plants under high salt conditions. It was therefore postulated that overexpression of StDREB2 activates the expression of downstream genes that prevent chlorophyll decomposition, thus maintaining normal photosynthesis, and improving tolerance to high salt stress [49].

Since, the P5CS gene is assumed to be a target gene of DREB factors belonging to A5 group [14,50], the capacity of these transgenic potato plants to maintain a high proline content level is likely to be one of the key determinants of plant salt tolerance. Indeed, the over-expression of GmDREB1 in alfalfa [50] and GmDREB2 in tobacco [14], have led to an increase of free proline contents in transgenic plants in comparison to wild-type plants submitted to salt stress (Fig. 12A). Similarly, RT-PCR analysis revealed that the expression of StDREB2 increased P5CS transcript level and thus led to higher level of free proline accumulation (Fig. 12B).

The enhanced tolerance to salt stress exhibited by StDREB2 overexpressing potato lines strongly supports the idea that DREB proteins play a role in activating signaling pathways that are required for plant responses to abiotic stresses. Furthermore, the ABA regulated expression of StDREB2 suggests the potential involvement of this gene in the ABA signaling pathways. As far as we know, the research reported here is the first to describe characterization and transgenic overexpression of StDREB genes from potato plants.

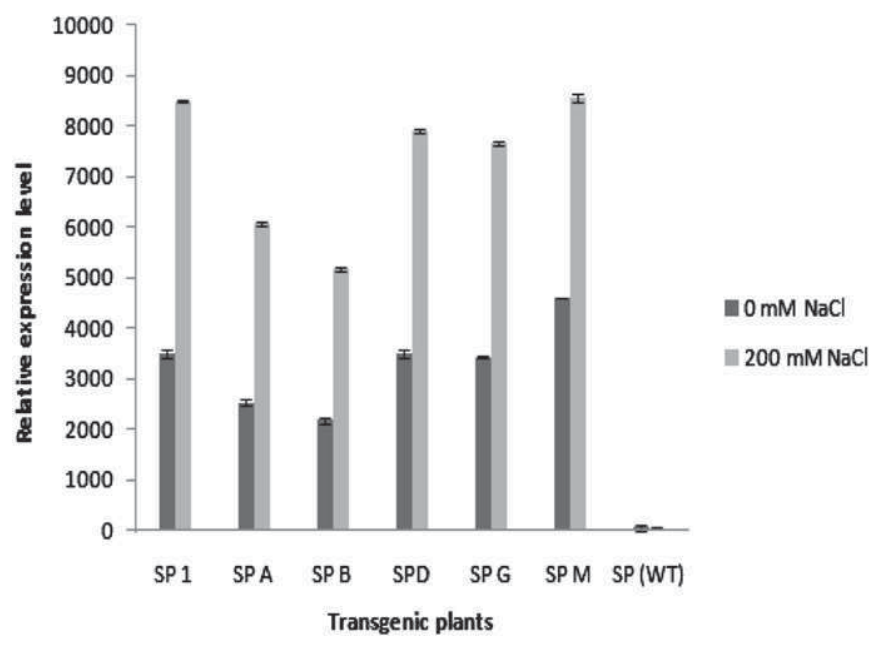

Fig. 7. Semi-quantitative RT-PCR analysis using pMDC32 primers flanking transgene in 0 and $200 \mathrm{mM}$ of salt stress. Graphical analyses using the Gel DocXR Gel Documentation System (BioRad). SP: Wild type. (SP 1, SP A, SP B, SP D, SP G and SP M): transgenic potato. Standard error (S.E.) was determined from three independent biological replicates, band densities were expressed in arbitrary units calculated by the analysis software.

\section{Materials and methods}

\subsection{Plant materials and stress treatments}

Potato plants cultivated in vitro (S. tuberosum L. cv. Nicola) were propagated in a solid MS basal medium [51] in a growth chamber conditions $\left(22^{\circ} \mathrm{C}\right.$, $16 \mathrm{~h}$ light $/ 8$ dark) under $250 \mu \mathrm{E} \mathrm{m}{ }^{-2} \mathrm{~s}^{-1}$ light intensity.

Abiotic stress treatments were applied on 3-week old in vitro cultivated plants for $0-24 \mathrm{~h}$. Low-temperature treatments were performed by transferring plants to a growth chamber set to $4{ }^{\circ} \mathrm{C}$ for different periods of time under the light and photoperiodic conditions described above. Dehydration was induced by the transfer of plants on aqueous MS medium supplemented with $10 \%$ $(\mathrm{w} / \mathrm{v})$ polyethylene glycol with an average molecular weight of 8000 (PEG 8000) to induce water deficit. Salinity and ABA treatments were performed by submerging the plant roots in aqueous MS medium supplemented with 100 or $200 \mathrm{mM} \mathrm{NaCl}$ or $50 \mu \mathrm{M}$ ABA. During those treatments, tubes containing potato vitro plants were sealed with parafilm, and the entire plants were harvested after 3, 6, 9 and 24 h treatments. All tissues harvested for nucleic acid extraction were weighed, immediately frozen in liquid nitrogen, and stored at $-70^{\circ} \mathrm{C}$ until use.

\subsection{Isolation and cloning of DREB constructs}

The full coding StDREB2 sequence (CDS) was found in the potato sequence Solanum Genetic Network (SGN) (http://www.sgn. cornell.edu) website. Specific primers designed from potato unigen (GenBank ID: SGNU275073) were chosen to amplify the

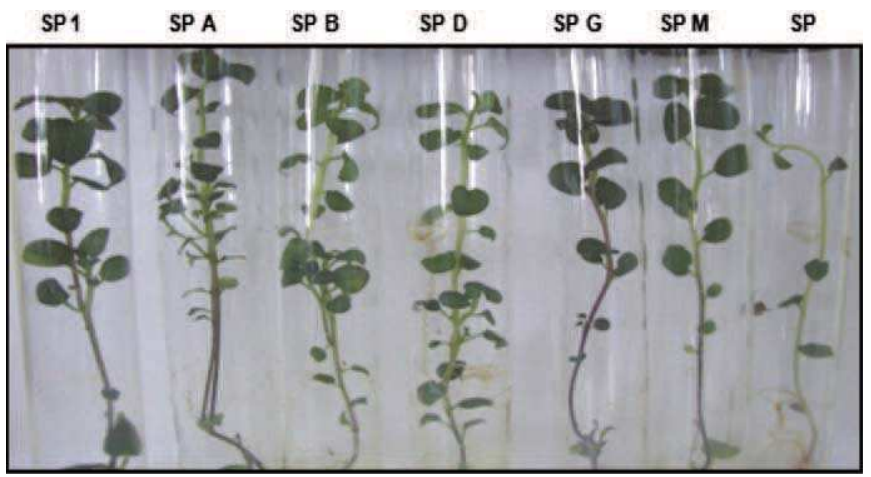

Fig. 8. Improved vigor of transgenic potato plants overexpressing StDREB2. Plants were cultivated under standard conditions. SP: Spunta untransformed plant (SP 1, SP A SP B, SP D, SP G and SP M): transgenic potato plants. 


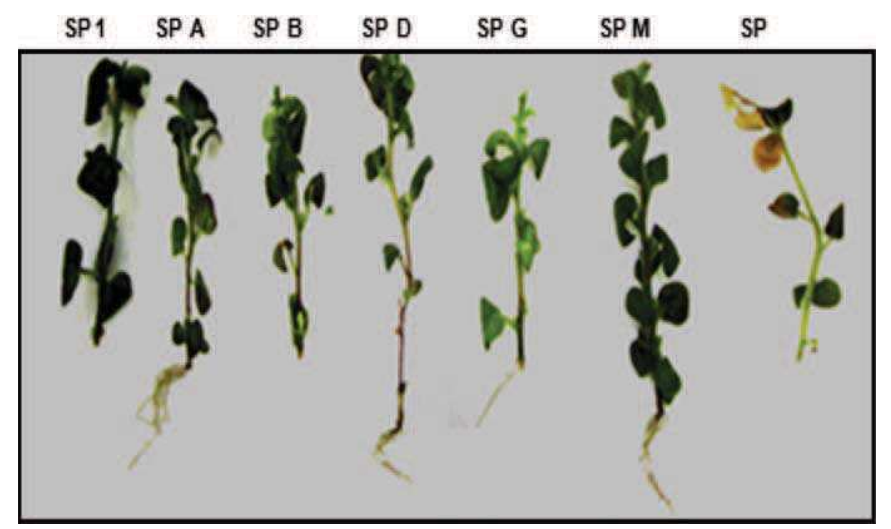

Fig. 9. Growth of transgenic potato under $200 \mathrm{mM} \mathrm{NaCl}$ stress after 40 days. SP: Spunta untransformed plant, (SP 1, SP A, SP B, SP D, SP G and SP M): transgenic potato plants. Transgenic plants and wild type ones were placed on MS liquid medium containing $200 \mathrm{mM} \mathrm{NaCl}$ for 40 days. As control, wild-type and transgenic plants were placed on MS liquid medium. Chlorophyll contents ( $\mathrm{mg} \mathrm{g}^{-1}$ fresh weight) were measured from $\mathrm{NaCl}$ treated leaves of 35S::StDREB2 transgenic and wild-type potato plants.

full-length sequence from the ATG to the STOP codon. The corresponding full-length cDNA was amplified from a mixture of different RNAs isolated from stem, roots, and leaves. The cloning of the StDREB2 gene was achieved by the Gateway cloning technology (Invitrogen). To generate overexpressing constructs, gene specific primers were designed spanning the ORF with AAAAAGCAGGCTTC and CAAGAAAGCTGGGTC adapters at the $5^{\prime}$ and $3^{\prime}$ ends respectively and primary amplicon was PCR amplified using the ISIS Taq DNA polymerase (Q-Biogene). For the addition of the attB sites, primary amplicons were used as templates and were amplified by using attB primers (attB1: 5'-ACAAGTTTGTACAAAAAAGCAGGCT- ${ }^{\prime}$ ' and attB2: 5'-ACCACTTTGTACAAGAAAGCTGGGT-3'). The PCR product was used for BP reaction to insert it in the pDONR207 entry vector (Invitrogen). Cloning of the amplicon (Gateway BP reaction) was carried out by adding $150 \mathrm{ng}$ of pDONR207 vector, $2 \mu \mathrm{l}$ of BP clonase II mix (Invitrogen) to $1 \mu \mathrm{l}$ of amplicon in $10 \mu \mathrm{l}$ reaction mixture adjusted to the desired volume by TE buffer. The reaction was left overnight at $25{ }^{\circ} \mathrm{C}$, then stopped by the addition of $1 \mu \mathrm{l}$ of proteinase $\mathrm{K}$ and incubated for $10 \mathrm{~min}$ at $37^{\circ} \mathrm{C}$. One to $10 \mu \mathrm{l}$ of the reaction mix was used to transform $50 \mu \mathrm{l}$ of competent DH-5 $\alpha$ cells. The cells were incubated with the DNA for $30 \mathrm{~min}$ on ice, heatshocked for $30 \mathrm{~s}$ at $42{ }^{\circ} \mathrm{C}$ in a water bath, incubated $5 \mathrm{~min}$ on ice, diluted with $250 \mu \mathrm{l}$ of Super Optimal broth with Catabolic repressor

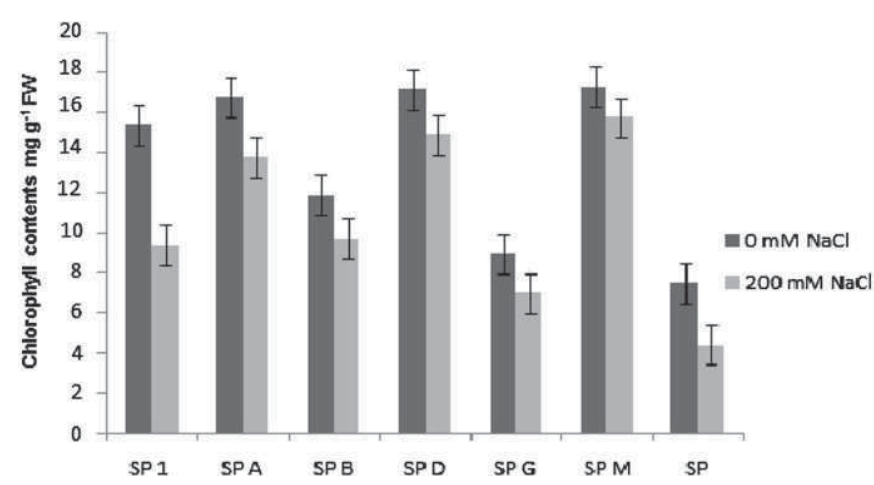

Fig. 10. Chlorophyll contents in transgenic potato leaf tissues submitted to salt treatment ( $200 \mathrm{mM} \mathrm{NaCl}$ ) for 40 days. Transgenic plants carrying the StDREB2 cDNA (SP 1, SP A, SP B, SP D, SP G and SP M) and wild-type plants (SP). The experiments were repeated three times. Data represent mean from three independent replicate.

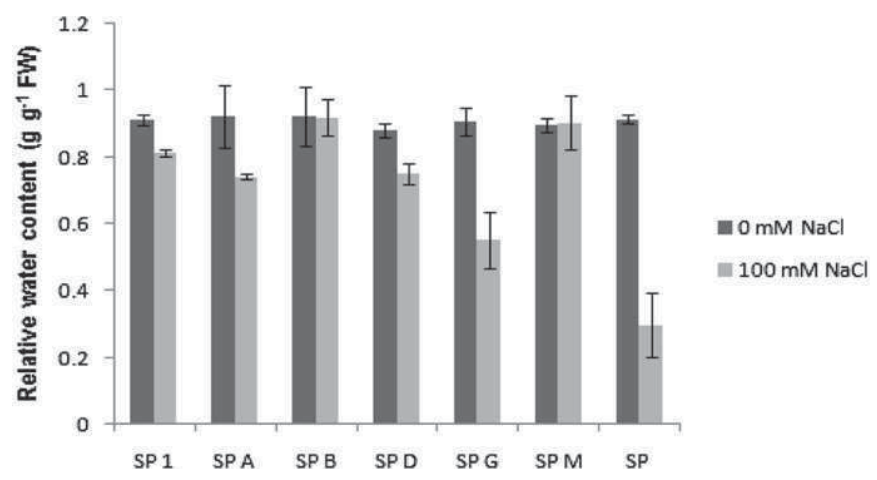

Fig. 11. Relative water contents of transgenic potato submitted to $100 \mathrm{mM} \mathrm{NaCl}$ treatment for 20 days. (SP 1, SP A, SP B, SP D, SP G and SP M): transgenic plants and (SP) wild-type plants.

(SOC) medium, shaken for $1 \mathrm{~h}$ at $37^{\circ} \mathrm{C}$ and finally plated on LB medium containing $10 \mu \mathrm{g} \mathrm{ml}^{-1}$ gentamycin.

The PCR made with vector-specific primers was carried out to check the presence of the insert. The amplification was performed as follows; $5 \mathrm{~min}$ at $95^{\circ} \mathrm{C}$, followed by 35 cycles of $1 \mathrm{~min}$ at $95^{\circ} \mathrm{C}$, $1 \mathrm{~min}$ at $60{ }^{\circ} \mathrm{C}$, elongation for $1 \mathrm{~min}$ at $72{ }^{\circ} \mathrm{C}$ and terminated by 10 min at $72{ }^{\circ} \mathrm{C}$.

The DREB cDNA was transferred from pDONR207 into a binary vector pMDC32 (Gateway LR reaction). This reaction was carried out by adding $4 \mu \mathrm{lmix}$ containing $150 \mathrm{ng}$ of pMDC32 [52], $1 \mu \mathrm{l}$ of LR clonase mix II (Invitrogen) to $1 \mu \mathrm{l}(150 \mathrm{ng})$ of the attL1 - DREB attL2 cassette DNA. The LR reaction was followed by the transformation and the screening of $E$. coli recombinant clones.

Database searches were performed using the National Center for Biotechnology Information (NCBI) BLAST search program. Alignment of the potato DREB protein with other structurally related DREB proteins was performed using the COBALT multiple alignment Tool from NCBI (www.ncbi.nlm.nih.gov).

Phylogenetic analysis was performed using the UPGMA method [53] with aid of MEGA4.0 Version software.

\subsection{Semi-quantitative RT-PCR analyses}

Total RNA was isolated from in vitro cultivated potato plants using the EZ-10 Spin column "Total RNA Mini preps Super Kit" (BIO BASIC INC), and the RNA was treated by DNaseI. Three separate biological replicates were used.

Semi-quantitative RT-PCR analyses were carried out using M-MuLV reverse transcriptase (BIO BASIC INC). Each cDNA sample was diluted $1 / 10 \mathrm{vol}$ and $1 \mu \mathrm{l}$ of the diluted cDNA was used for PCR amplification $\left(94^{\circ} \mathrm{C}\right.$ for $1 \mathrm{~min}, 60^{\circ} \mathrm{C}$ for $1 \mathrm{~min}, 72^{\circ} \mathrm{C}$ for $1 \mathrm{~min}$; in a final volume of $50 \mu \mathrm{l})$.

The ef1 $\alpha$ (elongation factor) gene (GenBank ID: AB061263) was used as constitutive gene marker. Its specific primers were designed as ef $1 \alpha \mathrm{F}$ ( $5^{\prime}$-ATTGGAAACGGATATGCTCCA- $\left.3^{\prime}\right)$ and ef $1 \alpha \mathrm{R}$ (5'-TCCTTACCTGAACGCCTGTCA-3').

The RT-PCR reaction of StDREB2 was perfomed by using specific primers of the binary vector pMDC32F (5'-TGTTTGAACGATCGGGGAAATTCGAGCTCC-3') and pMDC32R (5'-GGATCCCCGGGTACCGGGCC $-3^{\prime}$ ) under the same conditions as for the ef $1 \alpha$ constitutive gene. Twenty five cycles were performed to amplify the cDNA fragments. The expression pattern of P5CS putative target genes (SGN-U271255; PGSC0003DMG402026767 code in the genome of potato) was carried using the following specific primers P5CS F (5'-CCCACAGCAGCACAA-3') and P5CS R (5'-TTCGCAAGGGTATGAAG-3').

All RT-PCR expression assays were performed and analyzed at least three times in independent experiments. 


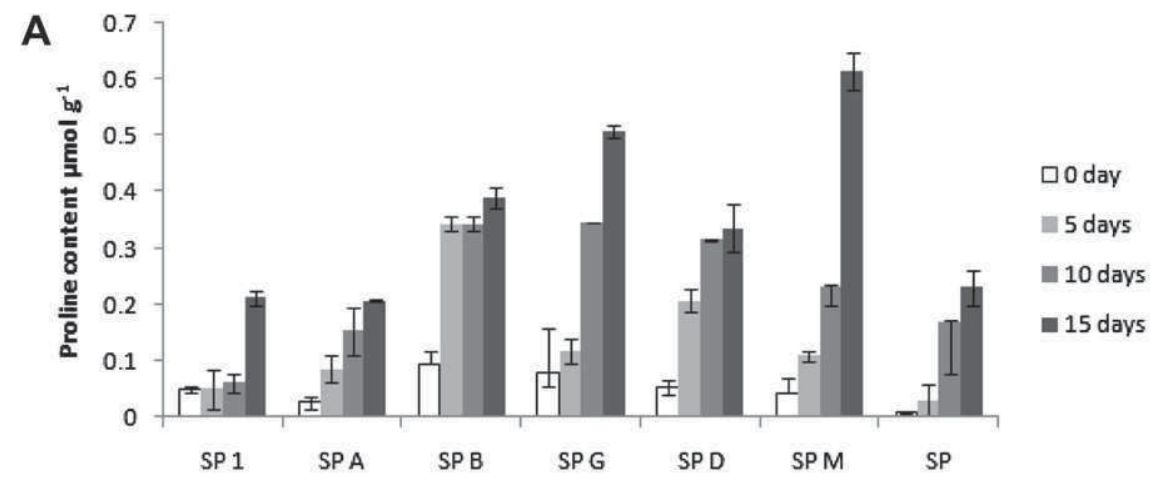

B

P5CS

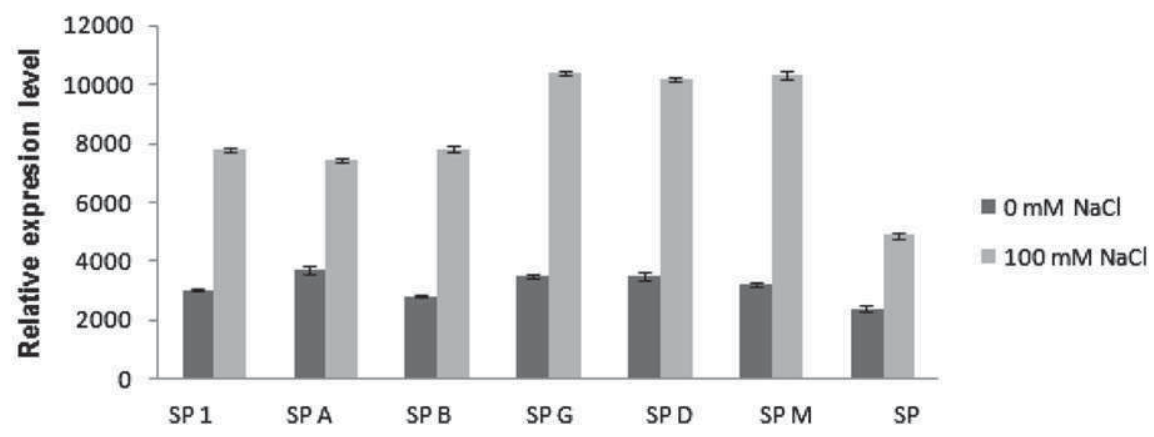

Fig. 12. A. Effects of salt stress on free proline contents of WT and transgenic potato plants grown under salt stress during 15 days. (SP 1 , SP A, SP B, SP D, SP G and SP M) transgenic plants and the SP WT plant. B. RT-PCR analysis of the expression of P5CS stress-induced gene after 10 days of culture under standard ( $0 \mathrm{mM} \mathrm{NaCl}$ ) or salt stress conditions ( $100 \mathrm{mM}$ $\mathrm{NaCl})$.

To analyze the salt stress response of transgenic plants, RT-PCRamplified products were visualized on ethidium bromide-stained $1.5 \%$ agarose gels and quantified using the Gel DocXR Gel Documentation System (BioRad). This software was used to calculate average band density, which was recorded and used in graphic analyses. Band density was calculated and graphed using Microsoft Excel. Error bar was determined from three separate biological replicates.

\subsection{Binary vectors and Agrobacterium strain}

The StDREB2 cDNA was inserted into the pMDC32 (Invitrogen) binary vector harboring the hygromycin phosphotransferase (hpt) gene. The StDREB2 cDNA (GenBank ID: JN125858) was inserted upstream of the CaMV $35 \mathrm{~S}$ doubled promoter. The recombinant binary vector (pMDC32::StDREB2; Fig. 4) was transferred into A. tumefaciens (LB4404 strain) as described by Hmida Sayari et al. [54].

The resulting $A$. tumefaciens recombinant strain harboring, the pMDC32::StDREB2 binary vector was used to transform potato explants.

\subsection{Plant transformation}

Plants from the Spunta commercial potato cultivar cultivated in vitro were propagated in a solid MS basal medium as described above. The internode transformation was performed as described by Bouaziz et al. [55]. Plant tissues were then transferred into a regeneration medium (MS medium supplemented with Naphthalene Acetic Acid (NAA) $0.2 \mathrm{mg} \mathrm{l}^{-1}$, zeatin $2 \mathrm{mg} \mathrm{l}^{-1}$ and gibberellic acid (GA3) $0.02 \mathrm{mg} \mathrm{l}^{-1}$ containing $250 \mathrm{mg} \mathrm{l}^{-1}$ cefotaxime and $2 \mathrm{mg} \mathrm{l}^{-1}$ hygromycin. Green shoots reaching $2 \mathrm{~cm}$ height were excised and transferred to test tubes containing solid MS basal medium supplemented with $3 \mathrm{mg} \mathrm{l}^{-1}$ hygromycin. Roots were obtained after $1-2$ weeks of culture.

\subsection{Analysis of DNA from transformed plants}

Genomic DNA was isolated from both transformed and nontransformed potato plantlets as described by Dellaporta et al. [56].

All PCR reactions were carried out in a thermocycler 2007 (Applied Biosystem) in a final volume of $25 \mu \mathrm{l}$ using 1 unit of Go Taq DNA polymerase (Promega), $100 \mathrm{ng}$ of specific primers and $50 \mathrm{ng}$ of DNA template. The PCR was performed using the following specific 35S promoter primers: P35S1: 5'-TGAGACTTTTCAACAAAGG-3'and P35S2: TCCTCTCCAAATGAAATGAA.

The amplification program started by a predenaturation at $94{ }^{\circ} \mathrm{C}$ for 5 min followed by 35 cycles of $94^{\circ} \mathrm{C}$ for $1 \mathrm{~min}$, annealing at $51^{\circ} \mathrm{C}$ for $1 \mathrm{~min}$ and elongation at $72^{\circ} \mathrm{C}$ for $1 \mathrm{~min}$. A $10 \mathrm{~min}$ final extension was done at $72{ }^{\circ} \mathrm{C}$. The amplification of StDREB2 cDNA was performed using the following specific primers of the binary vector pMDC32F: 5'-TGTTTGAACGATCGGGGAAATTCGAGCTCC-3' and pMDC32R: 5' GGATCCCCGGGTACCGGGCC-3'. The amplification program started by one denaturation cycle at $95{ }^{\circ} \mathrm{C}$ for $5 \mathrm{~min}$, followed by 35 cycles of denaturation for $20 \mathrm{~s}$ at $94^{\circ} \mathrm{C}$, annealing at $55^{\circ} \mathrm{C}$ for $1 \mathrm{~min}$ and elongation at $72{ }^{\circ} \mathrm{C}$ for $1 \mathrm{~min}$. A final elongation for $7 \mathrm{~min}$ at $72{ }^{\circ} \mathrm{C}$ was performed. The PCR products were analyzed by electrophoresis on $1.5 \%$ agarose gels in TBE buffer ( $89 \mathrm{mM}$ Tris base, 89 mM boric acid, 2 mM EDTA, pH 8.0).

\subsection{Stress treatment and determination of the content of chlorophyll}

Plantlets from transgenic and untransformed potato of $5 \mathrm{~cm}$ height were cultivated on MS liquid medium supplemented with 
$200 \mathrm{mM} \mathrm{NaCl}$ in a growth chamber for 40 days. Changes in leaf morphology and root elongation were followed during the treatment.

The chlorophyll content was evaluated Spectro-photometrically [57] on healthy and fully expanded leaves from wild-type and transgenic plants.

The leaf tissue $(0.01 \mathrm{~g})$ was lapped quickly by addition of $0.5 \mathrm{ml}$ of $100 \%$ acetone, and then $1 \mathrm{ml}$ of $80 \%$ acetone. The final volume was kept at $25 \mathrm{ml}$. The absorbance of chlorophyll $a$ and chlorophyll $b$ were measured at $663 \mathrm{~nm}$ and $645 \mathrm{~nm}$ respectively. The total chlorophyll content was evaluated as described by Arnon [57].

\subsection{Determination of proline content}

After being subjected to salt stress, leaves from transgenic and control plants were collected every 5 days to measure free proline. Proline analysis was carried out as described by Bates et al. [58].

\subsection{Measurement of relative water content}

The relative water content (RWC) of the WT and StDREB2 transgenic potato plants was determined as described by Yamasaki and Dillenburg [59]. Leaves were cut from in vitro cultivated potato plants and their fresh weight (FW) was measured. To determine turgid mass (TM), the leaves were floated in deionized water for $7 \mathrm{~h}$. Finally, the leaf samples were dried in an oven at $80^{\circ} \mathrm{C}$ for $48 \mathrm{~h}$ to obtain the dry weight (DW). The RWC was then calculated using the following formula:

$\mathrm{RWC}(\%)=[(\mathrm{FW}-\mathrm{DW}) /(\mathrm{TW}-\mathrm{DW})] \times 100$

\subsection{Electrophoretic mobility shift assay}

As a first step in this experiment, the target StDREB2 gene was over-expressed in $E$. coli. The full-length StDREB2 cDNA was amplified using the following primer pair: $5^{\prime}$-CCCCTCGAGATGATGGAAGGAGAA- $3^{\prime}$ and $5^{\prime}-5^{\prime}$ GGGGGATCCTCAATTATCTTCG TC $3^{\prime}-3^{\prime}$, and inserted into Xhol and BamH I sites of the pET14b $(+)$ expression vector (Invitrogen) and the recombinant plasmid was transferred into E. coli BL21(DE3) cells.

The expression of His tag StDREB2 fusion protein was induced for $4 \mathrm{~h}$ at $30^{\circ} \mathrm{C}$ by addition of $0.4 \mathrm{mM}$ IPTG (isopropyl- $\beta$-D-thiogalactoside). Recombinant bacteria were pelleted after the induction, and suspended in lysis buffer A (20 mM Tris-HCL, pH 8, $50 \mathrm{mM} \mathrm{NaCl}$ and $1 \%$ Triton X-100) then subjected to sonication. Bacterial lysates were then centrifuged, and the supernatant was used for protein purification. Purification of the recombinant StDREB2 protein was made using Ni-NTA affinity chromatography. StDREB2 protein was eluted with a linear imidazole gradient (50-400 mM imidazole in buffer A).

The potato P5CS-DRE motif promoter used in gel mobility shift assays has the following sequence: 5'-TTTCATAGCTAACCGAGATATCAAAGAA- $3^{\prime}$ while the mutated mDRE oligonucleotide is $5^{\prime}$-TTTCATAGCTATTTTTTTTATCAAAGAA-3' (the mutated nucleotides are in bold). These probes were biotin $5^{\prime}$ end labeled (Research tools). A sample of $0.02 \mathrm{pmol}$ of each probes was incubated with $200 \mathrm{ng}$ of purified StDREB2 protein in $20 \mu \mathrm{l}$ of $1 \times$ binding buffer (25 mM Hepes/KOH, pH 7.9, $1 \mathrm{M} \mathrm{KCl}, 200 \mathrm{mM}$ EDTA, 50\% glycerol, $1 \mu \mathrm{g} \mu \mathrm{l}^{-1} \mathrm{BSA}$ ) for $30 \mathrm{~min}$ on ice supplemented with $2 \mu \mathrm{g}$ Poly $(\mathrm{dI}-\mathrm{dC})$. The resulting DNA-protein complexes were loaded on $0.5 \times$ Tris-borate-EDTA, 6\% (30:0.8 acrylamide-bisacrylamide) polyacrylamide gel. The biotin end labeled DNA probe was detected using Peroxidase labeled anti-biotin and Immun-StarTM HRP chemiluminescent kit (BIO-RAD).

\section{Acknowledgments}

This work was financed by the Tunisian Ministry of High Education and Scientific Research. Authors are grateful to Dr. AnneLise Haenni from Institute Jacques (France) for reading and improving the manuscript and to Mofida Bouaziz-Kannoun from the "Institut Supérieur d'Administration des Affaires de Sfax" (Tunisia) for her kind help with the English language.

\section{References}

[1] V. Chinnusamy, K. Schumaker, J. Zhu, Molecular genetic perspectives on crosstalk and specificity in abiotic stress signalling in plants, J. Exp. Bot. 55 (2004) 225-236.

[2] C. Lata, M. Prasad, Role of DREBs in regulation of abiotic stress responses in plants, J. Exp. Bot. 62 (2011) 4731-4748.

[3] E.J. Stockinger, S.J. Gilmour, M.F. Thomashow, Arabidopsis thaliana CBF1 encodes an AP2 domain-containing transcriptional activator that binds to the C-repeat/DRE, a cis-acting DNA regulatory element that stimulates transcription in response to low temperature and water deficit, Proc. Natl. Acad. Sci. U S A 94 (1997) 1035-1040.

[4] M.F. Thomashow, So what's new in the field of plant cold acclimation? Lots!, Plant Physiol. 125 (2001) 89-93.

[5] S.S. Hussain, M.A. Kayani, M. Amjad, Transcription factors as tools to engineer enhanced drought tolerance in plants, Biotechnol. Prog. 27 (2011) 297-306.

[6] K. Nakashima, K. Yamaguchi-Shinozaki, Promoters and transcription factors in abiotic stress-responsive gene expression, in: Abiotic Stress Adaptation in Plants 2009, pp. 199-216.

[7] K.R. Jaglo, S. Kleff, K.L. Amundsen, X. Zhang, V. Haake, J.Z. Zhang, T. Deits, M.F. Thomashow, Components of the Arabidopsis C-repeat/dehydrationresponsive element binding factor cold response pathway are conserved in Brassica napus and other plant species, Plant Physiol. 127 (2001) 910-917.

[8] D.W. Choi, E.M. Rodriguez, T.J. Close, Barley Cbf3 gene identification, expression pattern, and map location, Plant Physiol. 129 (2002) 1781-1787.

[9] J.G. Dubouzet, Y. Sakuma, Y. Ito, M. Kasuga, E.G. Dubouzet, S. Miura, M. Seki, K. Shinozaki, K. Yamaguchi-Shinozaki, OsDREB genes in rice, Oryza sativa L., encode transcription activators that function in drought, high-salt and coldresponsive gene expression, The Plant J. 33 (2003) 751-763.

[10] Y. Sakuma, Q. Liu, J.G. Dubouzet, H. Abe, K. Shinozaki, K. Yamaguchi- Shinozaki, DNA-binding specificity of the ERF/AP2 domain of Arabidopsis DREBs, transcription factors involved in dehydration- and cold-inducible gene expression, Biochem. Biophys. Res. Commun. 290 (2002) 998-1009.

[11] T. Nakano, K. Suzuki, T. Fujimura, H. Shinshi, Genome-wide analysis of the ERF gene family in Arabidopsis and rice, Plant Physiol. 140 (2006) 411-432.

[12] P.K. Agarwal, P. Agarwal, M.K. Reddy, S.K. Sopory, Role of DREB transcription factors in abiotic and biotic stress tolerance in plants, Plant Cell. Rep. 86 (2006) 1263-1274.

[13] J.P. Hong, W.T. Kim, Isolation and functional characterization of the $\mathrm{Ca}$ DREBLP1 gene encoding a dehydration-responsive element binding-factorlike protein 1 in hot pepper (Capsicum annuum L. cv Pukang), Planta 220 (2005) 875-888.

[14] M. Chen, Q.Y. Wang, X.G. Cheng, Z.S. Xu, L.C. Li, X.G. Ye, L.Q. Xia, Y.Z. Ma, GmDREB2, a soybean DRE-binding transcription factor, conferred drought and high-salt tolerance in transgenic plants, Biochem. Biophys. Res. Commun. 353 (2007) 299-305.

[15] X. Wang, X. Chen, Y. Liu, H. Gao, Z. Wang, G. Sun, CkDREB gene in Caragana korshinskii is involved in the regulation of stress response to multiple abiotic stresses as an AP2/EREBP transcription factor, Mol. Biol. Rep. 38 (2011) $2801-2811$.

[16] Y.G. Shen, W.K. Zhang, S.J. He, J.S. Zhang, Q. Liu, S.Y. Chen, An EREBP/AP2-type protein in Triticum aestivum was a DRE-binding transcription factor induced by cold, dehydration and ABA stress, Theor. Appl. Genet. 106 (2003a) 923-930.

[17] C. Egawa, F. Kobayashi, M. Ishibashi, T. Nakamura, C. Nakamura, S. Takumi, Differential regulation of transcript accumulation and alternative splicing of a DREB2 homolog under abiotic stress conditions in common wheat, Genes Genet. Syst. 81 (2006) 77-91.

[18] P. Agarwal, P.K. Agarwal, S. Nair, S.K. Sopory, M.K. Reddy, Stress inducible DREB2A transcription factor from Pennisetum glaucum is a phosphoprotein and its phosphorylation negatively regulates its DNA binding activity, Mol. Genet. Genomics 277 (2007) 189-198.

[19] F. Qin, M. Kakimoto, Y. Sakuma, K. Maruyama, Y. Osakabe, L.S. Tran, K. Shinozaki, K. amaguchi-Shinozaki, Regulation and functional analysis of ZmDREB2A in response to drought and heat stresses in Zea mays L, The Plant J. 50 (2007) 54-69.

[20] C. Lata, S. Bhutty, R.P. Bahadur, M. Majee, M. Prasad, Association of a SNP in a novel DREB2-like gene SiDREB2 with stress tolerance in foxtail millet [Setaria italica (L.)], J. Exp. Bot. 62 (2011) 3387-3401.

[21] P.K. Agarwal, B. Jha, Transcription factors in plants and ABA dependent and independent abiotic stress signaling, Biol. Plant. 54 (2010) 201-212. 
[22] Y. Fujita, M. Fujita, K. Shinozaki, K. Yamaguchi-Shinozaki, ABA mediated transcriptional regulation in response to osmotic stress in plants, J. Plant Res. 124 (2011) 509-525.

[23] Z.S. Xu, M. Chen, L.C. Li, Y.Z. Ma, Functions and application of the AP2/ERF transcription factor family in crop improvement, J. Integr. Plant Biol. 53 (2011) $570-585$.

[24] S.J. Lee, J.Y. Kang, H.J. Park, M.D. Kim, M.S. Bae, H.I. Choi, S.Y. Kim, DREB2C interacts with ABF2, a bZIP protein regulating abscisic acid-responsive gene expression, and its overexpression affects abscisic acid sensitivity, Plant Physiol. 153 (2010) 716-727.

[25] F. Kobayashi, M. Ishibashi, S. Takumi, Transcriptional activation of Cor/Lea genes and increase in abiotic stress tolerance through expression of a wheat DREB2 homolog in transgenic tobacco, Transgenic Res. 17 (2008) 755-767.

[26] D. Kizis, M. Pages, Maize DRE-binding proteins DBF1 and DBF2 are involved in rab17 regulation through the drought responsive element in an ABAdependent pathway, The Plant J. 30 (2002) 679-689.

[27] P. Agarwal, P.K. Agarwal, A.J. Joshi, S.K. Sopory, M.K. Reddy, Overexpression of PgDREB2A transcription factor enhances abiotic stress tolerance and activates downstream stress-responsive genes, Mol. Biol. Rep. 37 (2010) 1125-1135.

[28] M. Kasuga, S. Miura, K. Shinozaki, K. Yamaguchi-Shinozaki, A combination of the Arabidopsis DREB1A gene and stress inducible rd29A promoter improved drought and low-temperature stress tolerance in tobacco by gene transfer, The Plant Cell Physiol. 45 (2004) 346-350.

[29] A. Pellegrineschi, M. Reynolds, M. Pacheco, R.M. Brito, R. Almeraya K. Yamaguchi-Shinozaki, D. Hoisington, Stress-induced expression in wheat of the Arabidopsis thaliana DREB1A gene delays water stress symptoms under greenhouse conditions, Genome 47 (2004) 493-500.

[30] B. Hong, Z. Tong, Q.H. Li, C. Ma, M. Kasuga, K. Yamaguchi-Shinozaki, J.P. Gao, Regeneration and transformation through somatic embryogenesis, and determination of cold stress tolerance in ground cover Chrysanthemum cv. Fall color, Sci. Agric. Sin. 39 (2006) 1443-1450.

[31] M.T. Pino, J.S. Skinner, Z. Jeknic, P.M. Hayes, A.H. Soeldner, M.F. Thomashow, T.H.H. Chen, Ectopic AtCBF1 overexpression enhances freezing tolerance and induces cold acclimation-associated physiological modifications in potato Plant Cell. Environ. 31 (2008) 393-406.

[32] F. Celebi-Toprak, B. Behnam, G. Serrano, M. Kasuga, K. Yamaguchi- Shinozaki, H. Naka, J.A. Watanabe, S. Yamanaka, K.N. Watanabe, Tolerance to salt stress of the transgenic tetrasomic tetraploid potato, Solanum tuberosum cv. Desiree appears to be induced by the DREB1A gene and rd29A promoter of Arabidopsis thaliana, Breed. Sci. 55 (2005) 311-319.

[33] B. Behnam, K. Kikuchi, F. Celebi-Toprak, S. Yamanaka, M. Kasuga, K. Yamaguchi-Shinozaki, K.N. Watanabe, The Arabidopsis DREB1A gene driven by the stress-inducible rd29A promoter increases salt-stress tolerance in tetrasomic tetraploid potato (Solanum tuberosum) in proportion to its copy number, Plant Biotechnol. 23 (2006) 169-177.

[34] B. Behnam, A. Kikuchi, F. . Celebi -Toprak, M. Kasuga, K. Yamaguchi- Shinozaki, K.N. Watanabe, Arabidopsis rd29A: DREB1A enhances freezing tolerance in transgenic potato, Plant Cell. Rep. 26 (2007) 1275-1282.

[35] A. Landy, Dynamic, structural, and regulatory aspects of lambda site-specific recombination, Ann. Rev. Biochem. 58 (1989) 913-949.

[36] L. Liu, M.J. White, T.H. MacRae, Transcription factors and their genes in higher plants functional domains, evolution and regulation, Eur. J. Biochem. 262 (1999) 247-257.

[37] G.P. Xue, C.W. Loveridge, HvDRF1 is involved in abscisic acid mediated gene regulation in barley and produces two forms of AP2 transcriptional activators, interacting preferably with a CT-rich element, The Plant J. 37 (2004) 326-339.

[38] Z.S. Xu, Z.Y. Ni, Li . Liu, N.N. Li, L.C. Li, M. Chen, Y.Z. Ma, Characterization of the TaAIDFa gene encoding a CRT/DRE-binding factor responsive to drought, high-salt, and cold stress in wheat, Mol. Genet. Genomics 280 (2008) 497-508.
[39] Y.G. Shen, W.K. Zhang, D.Q. Yan, B.X. Du, J.S. Zhang, Q. Liu, S.Y. Chen, Characterization of a DRE-binding transcription factor from a halophyte Atriplex hortensis, Theor. Appl. Genet 107 (2003b) 155-161.

[40] X.P. Li, A.G. Tian, G.Z. Luo, Z.Z. Gong, J. Zhang, S.Y. Chen, Soybean DRE-binding transcription factors that are responsive to abiotic stresses, Theor. Appl. Genet. 110 (2005) 1355-1362.

[41] AJ. Conner, M.C. Christey, Plant breeding and seed marketing options for introduction of transgenic insect-resistant crops, Biocontrol Sci. Technol. 4 (1994) 463-473.

[42] M. Tanga, X. Liua, H. Dengb, S. Shena, Over-expression of JcDREB, a putative AP2/EREBP domain-containing transcription factor gene in woody biodiesel plant Jatropha curcas, enhances salt and freezing tolerance in transgenic Arabidopsis thaliana, Plant Sci. 181 (2011) 623-631.

[43] S.Q. Gao, M. Chen, L.Q. Xia, H.J. Xiu, Z.S. Xu, L.C. Li, C.P. Zhao, X.G. Cheng, Y.Z. Ma, A cotton (Gossypium hirsutum) DRE-binding transcription factor gene, GhDREB, confers enhanced tolerance to drought, high salt, and freezing stresses in transgenic wheat, Plant Cell. Rep. 28 (2009) 301-311.

[44] N. Verbruggen, C. Hermans, Proline accumulation in plants: a review, Amino Acids 35 (2008) 753-759.

[45] K. Kazan, Negative regulation of defence and stress genes by EAR-motifcontaining repressors, Trends Plant Sci. 11 (2006) 109-112.

[46] U. Fischer, W. Dröge-Laser, Overexpression of NtERF5, a new member of the tobacco ethylene response transcription factor family, enhances resistance to tobacco mosaic virus, Mol. Plant Microbe. Interact. 17 (2004) 1162-1171.

[47] M. Ohta, K. Matsui, K. Hiratsu, H. Shinshi, M. Ohme-Takagi, Repression domains of class II ERF transcriptional repressors share an essential motif for active repression, The Plant Cell 13 (2001) 1959-1968.

[48] M. Denekamp, S.C. Smeekens, Integration of wounding and osmotic stress signals determines the expression of the AtMYB102 transcription factor gene, Plant Physiol. 132 (2003) 1415-1423.

[49] H. Zhang, Z. Huang, B. Xie, O. Chen, X. Tian, X. Zhang, H. Zhang, X. Lu, D. Huang, R. Huang, The ethylene, jasmonate, abscisic acid and $\mathrm{NaCl}$ responsive tomato transcription factor JERF1 modulates expression of GCC box-containing genes and salt tolerance in tobacco, Planta 220 (2004) $262-270$.

[50] T. Jin, O. Chang, W. Li, D. Yin, Z. Li, D. Wang, B. Liu, L. Liu, Stress-inducible expression of GmDREB1 conferred salt tolerance in transgenic alfalfa, Plant Cell. Tiss. Organ Cult. 100 (2010) 219-227.

[51] T. Murashige, F. Skoog, A revised medium for rapid growth and bioassays with tobacco tissue cultures, Plant Physiol. 15 (1962) 473-497.

[52] K.W. Earley, J.R. Haag, O. Pontes, K. Opper, T. Juehne, K. Song C.S. Pikaard, Gateway-compatible vectors for plant functional genomics and proteomics, The Plant J. 45 (2006) 616-629.

[53] C.D. Michener, R.R. Sokal, A quantitative approach to a problem of classification, Evolution 11 (1957) 490-499.

[54] A. Hmida-Sayari, R. Gargouri-Bouzid, A. Bidani, L. Jaoua, A. Savouré, S. Jaoua, Overexpression of D1-pyrroline-5-carboxylate synthetase increases proline production and confers salt tolerance in transgenic potato plants, Plant Sci. 169 (2005) 746-752.

[55] D. Bouaziz, M. Ayadi, A. Bidani, S. Rouis, O. Nouri-Ellouz, R. Jellouli, N. Drira R. Gargouri-Bouzid, A stable cytosolic expression of VH antibody fragment directed against PVY NIa protein in transgenic potato plant confers partial protection against the virus, Plant Sci. 176 (2009) 489-496.

[56] S.L. Dellaporta, J. Woods, J.B. Hicks, A plant DNA minipreparation: version II, Plant Mol. Biol. Rep. 1 (1983) 19-21.

[57] D.L. Arnon, A copper enzyme is isolated chloroplast polyphenol oxidase in Beta vulgaries, Plant Physiol. 24 (1949) 1-15.

[58] L.E. Bates, R.P. Waldren, I.D. Teare, Rapid determination of free proline for water stress studies, Plant Soil 39 (1973) 205-207.

[59] S. Yamasaki, L.R. Dillenburg, Measurements of leaf relative water content in araucaria angustifolia, Rev. Bras. Fisiol. Veg. 11 (1999) 69-75. 